\title{
Uma revisitação «espetacular»: presença francesa no teatro vicentino
}

Olinda Kleiman

Recebido em 19 jul 2012 - Aprovado em 17 set 2012

\section{Resumo}

Inscrevendo-se numa reflexão mais ampla, simultaneamente focalizada nas releituras do passado no presente e nas culturas entre fronteiras, este trabalho toma por base o teatro vicentino, paradigma dessa cultura do outro - estrangeiro ou predecessor - que os tempos tinham em alto preço. Durante as três primeiras décadas do século XVI, entre 1502 e 1536, época de abertura e de incessantes intercâmbios entre cortes, com o seu séquito de artistas, Gil Vicente presidiu aos divertimentos de uma corte já por si bilingue e bicultural. Marcadamente devedor à literatura vizinha, o seu teatro não despreza outras influências. Entre elas, a francesa ocupa um lugar relevante, visivel quer na retomada de temas, de personagens ou ainda de elementos linguísticos, quer na imitação de gêneros e de formas. O presente estudo tenta não se limitar à constatação de uma influência; questiona o texto e os próprios mecanismos do espetáculo para avaliar a forma como esse teatro perfeitamente se coadunava com as culturas europeias, de que a sua veia jocosa se alimentava. Confronta-se um texto - a cena que põe em presença o Juiz e a Moça de Floresta de enganos - com o seu «hipotexto»-uma das novelas que compõem o livro das Cent nouvelles nouvelles oferecido ao duque de Borgonha por volta de 1461-2. O propósito é também o de recolher algum esclarecimento sobre dominios que mal conhecemos, tal como, precisamente, o que respeita à cultura do poeta dramaturgo, muito mal avaliada pela interpretação séria de um texto largamente manipulado e excessivamente manipulador.

Palavras-chave: Teatro vicentino; influência francesa; reescrita; cultura do equívoco. 
«Releituras do passado no presente». O tema submetido à reflexão, no âmbito da preparação do presente número da Gragoatá, convida a - ou pelo menos deixa lugar para - uma dupla perspectivação da problemática. O assunto aqui tratado visa assim examinar simultaneamente os laços que as artes, literárias e do espetáculo neste caso, tecem com formas de criação anteriores, ilustrando o diálogo que as obras criam com um passado relativamente recente, e, simultaneamente, os ecos que desse duplo passado se fazem ouvir no nosso próprio presente. Esta relação que, através delas, estreitamente se estabelece entre as três temporalidades, oferece uma bela oportunidade de verificar até que ponto as lições do passado, assim transmitidas, são necessárias ao presente mas também até que ponto invariavelmente se renovam de século para século, sem grande resultado, ao que parece, num eterno recomeço. É prova dessa permanência o recente acontecimento que colocou Dominique Strauss Kahn nas luzes da ribalta, dando ensejo a uma mediatização mundial sem precedentes. Quer pelas posturas das duas figuras implicadas, quer pelas funções por elas exercidas, o escabroso episódio apresenta uma edificante analogia com a famosa cena de Floresta de enganos, que, adaptada ao palco a partir de uma das novelas oferecidas cerca de oitenta anos antes ao duque de Borgonha, constitui uma cabal demonstração da perfeita adequação do teatro vicentino à atualidade da época que o precedeu e à nossa própria atualidade, social, política, ou simplesmente humana, universal. $\mathrm{O}$ assunto, obsceno, lúdico e teatral, é do gosto dos homens do tempo, de cuja cultura do riso Gil Vicente alimenta a sua poética do cômico e do incôngruo. Não é tanto do nosso, por não compreendermos as suas subtilezas e porque, segundo a fórmula de Baudelaire, esse riso «já não é o nosso». Mas assenta igualmente numa realidade tangível, que a literatura incessantemente questiona, denuncia, ferozmente satiriza, ou de que meramente se regozija, rindo dos nossos vícios, pequenos ou maiores. Se bem que cada tempo possa puxar o sentido para a dimensão que melhor lhe apraz, a favor da ética ou a favor do lúdico, o fato é que o encontro inegavelmente se realiza, entre as três temporalidades aqui em questão, através da ligeireza da anedota inicial que diz o homem de todos os lugares e de todas as idades, de todos os passados, e também do presente, como é próprio da literatura.

Abordando o ponto que diretamente nos interessa, a presença francesa, palpável no teatro vicentino, pode, em parte, ser aquilatada de forma cientificamente satisfatória, através da confrontação dos textos. Vários estudiosos se dedicaram a esse trabalho; limitar-me-ei a fazer uma apresentação sintética das suas conclusões, sublinhando de imediato que a questão da relação profunda de Gil Vicente com essa cultura que ocupa um lugar de relevo, se bem que em nada comparável com a da vizinha Castela, intrigou e continua a intrigar. Para tentar trazer a minha 
pedra ao edifício, focalizarei em seguida a minha atenção sobre um exemplo de reescrita de uma das Cent nouvelles nouvelles, texto acima referido, pelo qual em tempos me interessei e que me abriu perspectivas inesperadas no campo da exegese do texto vicentino (KLEIMAN, 1996, p. 33-56). Para além da questão em análise, que esta reprise corrobora, convém dizer de antemão que a tonalidade do texto original, bem como o seu contexto específico de produção e de difusão, constituem elementos fundamentais para a reflexão. Permitirão estes, em particular, matizar certas conclusões derivadas do uso e abuso do conceito de "popular", que merece ser reconsiderado a um duplo título: primeiro, como qualificativo a bem dizer adstrito à obra vicentina e que de certa forma se impôs como uma etiqueta indicadora das próprias origens do poeta; parece no entanto evidente que, na falta de documentos de uma outra natureza, não é o texto, manipulador à souhait, que nos pode esclarecer sobre o assunto; segundo, como epíteto designativo de uma cultura, o termo é mistificador quanto às mentalidades e gostos do tempo e, por via de regra, quanto às práticas em vigor e às formas de abordagem do espetáculo próprias da época, para nós hoje herméticas. A parte deste trabalho relativa ao estudo da adaptação da novela tratará de desfazer aquilo que me aparece como um equívoco.

\section{As formas dessa presença}

A presença francesa é amplamente atestada na obra vicentina. Manifesta-se quer por uma retomada de temas, quer por alguns rudimentos de língua, quer ainda pela ligação com um hipotexto reconhecível. Reveste formas diversas. Algumas são patentes no jogo de cena e apreensíveis por todos; outras são menos facilmente detectáveis. Da consciência exata das primeiras depende a compreensão profunda da representação e, em corolário, o pleno sucesso do momento festivo que em grande parte assenta numa tripla cumplicidade: entre público e dramaturgo, entre público e ator, cumplicidade coletiva da sala. As segundas têm sobretudo a ver com o substrato cultural. $\mathrm{O}$ conhecimento das influências suscetíveis de terem operado na elaboração do espetáculo poderá favorecer uma abordagem em

1 Para todos os textos vicentinos aqui citados, a edição de referência é a Copilaçam de toda las obras de Gil Vicente, reprodução fac-similada da edição de 1562 - Lisboa: Biblioteca Nacional, 1928. As referências remetem para uma numeração seguida das linhas tais como aparecem no texto original, sem ter em conta as didascálias. profundidade e alimentar um júbilo pessoal, mas não é indispensável nem à compreensão imediata nem à cumplicidade jocosa. Examinemos os dois casos:

\section{Primeiro caso: uma presença visível}

Sublinharei duas situações, eventualmente, mas não necessariamente, interligadas. Trata-se, por um lado, da intervenção de uma personagem que assume o papel do «Francês», assim designado, como no Auto da Fama, ou identificável pelo seu idioma, como no Auto das Fadas ${ }^{1}$. E trata-se, por outro lado, da utilização 
da língua francesa em cena. Podemos imaginar que a nobre assistência, público privilegiado do poeta dramaturgo encarregado de organizar as festas de uma das mais prestigiadas cortes da época, era capaz de a detetar senão de a compreender. Ao lado dos dois sistemas linguísticos dominantes, outros idiomas - hebraico, árabe, basco, francês, italiano - intervêm nos autos, de forma mais ou menos esporádica, descosida, e deturpada, geralmente em situação de misturas exóticas extravagantes, cacofónicas, participando do cómico e do espetacular. O processo não é próprio do teatro vicentino. Dentro desse esquema, um lugar particular é reservado às personagens do Italiano e do Francês e das respetivas línguas que, contrariamente às outras - excetuando o castelhano - , não se limitam a simples expressões avulsas mas dão ensejo à utilização de frases seguidas.

No que respeita ao tratamento da personagem do Francês, sem me demorar, relembro que, no Auto da Fama, em torno da figura alegórica que representa a glória portuguesa, o Francês, como o Castelhano e o Italiano, pelo seu estatuto prestigioso no seio das cortes europeias da época, é essencialmente usado como objeto de afirmação do Português, a cuja supremacia serve de esteio: a escolha é sintomática do reconhecimento implícito da alta qualidade de um povo que o Português excede, como não podia deixar de ser.

Do ponto de vista linguístico, se a presença do francês é atestada neste auto, curiosamente o idioma não é associado ao personagem que o deveria falar. $\mathrm{O}$ discurso dos três pretendentes integra indistintamente elementos dos três idiomas, produzindo uma «cacofonia verbal», à moda de uma «ensalada [que] faz lembrar as fratrasies francesas» (TEYSSIER, 2005, p. 334-335) mas que repousa também no jogo de massacre das línguas visando efeitos cômicos.

No Auto das Fadas, a presença da língua francesa reveste modos mais interessantes. Serão possivelmente originais, como Paul Teyssier tende a crer (p. 345). Mas há certezas. Jean Girodon, baseando-se nas rimas e numa visível «submissão» do texto português ao francês, emite a hipótese de Gil Vicente ter, senão copiado, pelo menos imitado um passo de «uma possível diablerie de um mistério do Norte» de França (TEYSSIER, p. 345). Na impossibilidade de o demonstrar, aquilo que se poderá dizer é que os modos se tornam aqui mais nítidos. Nas réplicas por vezes impenetráveis que o Diabo dirige à Feiticeira Genebra Pereira, os estudiosos - Paul Teyssier, Jean Girodon, Pierre Groult, e numa época mais recente Jacqueline Picoche - conseguiram desvendar frases completas de francês repleto de picardismos. A questão não era fácil e muito de misterioso subsiste. $\mathrm{O}$ francês do Diabo não é imediatamente reconhecível, mesmo por especialistas. A didascália a anunciar a entrada do Diabo, convocado por Genebra Pereira, a quem, diz o texto, «fala em língua picarda», dialeto do 
Norte de França, constituiu certamente uma preciosa indicação, a partir da qual se pôde iniciar uma investigação. Não vou refazer aqui uma demonstração que já foi feita. Retomarei dois exemplos que me servirão de ponto de partida para levantar questionamentos relativos a um eventual conhecimento não só da cultura mas da língua francesa, e não só pelo dramaturgo mas pelo seu público. Ao chegar, o Diabo dirige-se à Feiticeira nestes termos: ${ }^{2}$

Oo dame jordene

Vu seae la bien trovee!

Tu es fause te humeyne

Sou ye vous esposée!

Responde-lhe esta:

Que lingoagem he essa tal?

Huy, e ele fala aravia!

Olh[a]de o nabo de Turquia!

Falade aramaa a Portugal! (v. 209-212).

Tirando o terceiro verso, que é um insulto proferido em aparte, as palavras do Diabo são uma saudação convencional, formulada em francês e não em picardo. Para além do dito insultante, o cômico resulta aqui do recurso à língua estrangeira, que ainda por cima não está ao alcance da interlocutora, como ela própria faz valer. Nestas primeiras réplicas, de entrada em contacto das duas personagens, o processo amplamente praticado, daquilo que poderemos considerar como um desajuste de linguagens, é sem qualquer dúvida um processo auto suficiente no que concerne ao riso e ao espetacular. Todavia, para que seja realmente operante e se assegure a sua duração, não parece viável que este processo se possa manter nessa mera linha de uma justaposição de duas línguas, e que as réplicas do Diabo, personagem cômico por excelência, escapem totalmente ao auditório. Como imaginar que o público possa ter aguentado um jogo duradouro, assente nesse simples artifício, e com isso se possa ter contentado? Como imaginar que, por seu turno, Gil Vicente tenha desconhecido as potencialidades cômicas das palavras, meramente incôngruas algumas, incôngruas até à obscenidade outras, que ele utiliza aqui numa língua estrangeira mas de que faz um uso tão abundante quanto magistral na sua própria língua? A incongruência é um dos recursos prediletos do cômico vicentino e dos autores

2 "Oh dame Jourdaine,/ vous soyez la bien trouvée !/ (Tu es fausseté humaine)/ Soyez vous épousée!)" Em português atualizado: "Ó senhora Jourdaine/ Bem encontrada sejais!/ (humana)/

Bem casada vos vejais! (v. 205-208)." do seu tempo: uma tal coincidência não pode ser um mero acaso. E, imaginando que o poeta tivesse "copiado" um qualquer texto, como foi conjeturado, que ele soubesse, sem mais, o significado das palavras de que se aproveita, o que é que justificaria o seu emprego se não fossem entendidas pelo público? Esta é certamente uma pergunta que tem alguma pertinência no segundo exemplo a que recorrerei. 
Um pouco mais adiante, o Diabo faz esta "saída" que bem parece ter dado algum trabalho aos investigadores: ${ }^{3}$

Tu aspete de bem la mer.

E eis a resposta da Feiticeira:

Hui pété que pode ser? (v. 232.)

Se bem que o verso 231 tenha um sentido global coerente, que é em substância, «aquilo que tu dizes ou nada, vem a dar ao mesmo", é porém sobre o verbo péter que tudo repousa. Mostra-o a reação da Feiticeira, que repete a palavra como se fosse a única do verso ou pelo menos a única em língua estrangeira, a única cujo sentido lhe escapa. Não é o caso. O que justifica que o termo seja isolado dos outros, e por isso destacado, é o seu valor como obscenidade, no âmbito de uma estética do incôngruo e do riso que vale por si só, e que Gil Vicente duplamente explora, através do fenômeno de repetição da palavra impronunciável, do indizível que aqui melhor se diz disfarçado na língua outra. Outros exemplos se integram claramente nessa estética, através de uma poética da invectiva, cujos efeitos teatrais são bem conhecidos desde Aristófanes (SAETTA-COTTONE, 2005). A figura do Diabo é perita no gênero. É pois difícil acreditar que Gil Vicente tivesse criado ou "copiado" este papel tão teatral, se este não pudesse ser apreendido em todos os seus sentidos. Salvo a admitir que o dramaturgo se divertisse à custa do seu auditório, servindo-lhe obscenidades que não compreendia, tudo leva a crer que esse vocabulário era conhecido pelas duas partes e que só assim a cumplicidade teatral se podia plenamente cumprir. Tudo isto é natural, ao gosto e ao alcance de um público que hoje se diria pouco exigente mas que não era nem "popular", nem especificamente português. Só que, para que pelo menos neste caso o riso despoletasse - e esse era o objetivo -, era indispensável que o público, pelo menos parte dele, compreendesse. É a relação com o cômico que está em causa: os pormenores são importantes e era necessário ultrapassar a mera circunstância do bric-à-brac da mistura de línguas. Para mim, como para Paul Teyssier (p. 346), Gil Vicente tinha provavelmente conhecimentos de francês e o seu público, que era um público culto, habituado às visitas de e a outras cortes, também. Não significa isso que dominasse a língua francesa mas que conhecia o necessário para a manipular, no sentido de lhe imprimir formas e significados teatralmente conseguidos.

3 "Tu as pété dedens la Tradução em português:

" Deste um peido no mar. (v. 231)"

\section{Uma presença menos palpável}

Para além desta presença concreta, deixam-se apreender, na profundidade do texto - parte duradoura que nos é transmi- 
tida do espetáculo efêmero -, as marcas de uma cultura que está longe de se restringir às fronteiras da Península. Como mestre de cerimônias dos monarcas, Gil Vicente desempenhava um papel de primeiro plano num cerimonial que não se concebia como simples manifestação de grandeza para uso interno mas que estava todo ele voltado para o exterior. As relações entre cortes eram permanentes; os artistas viajavam no séquito dos seus senhores; Gil Vicente estava no galarim para acompanhar os eventos, ver, debater, conhecer e beneficiava com certeza de uma informação de primeira mão sobre as modas vigentes nas outras cortes europeias, em matéria de divertimentos, de festas, de criação artística. Subscrevo plenamente a opinião que Georges Le Gentil formulou a partir da análise da conhecida cena entre Todo o Mundo e Ninguém e do seu confronto com as outras literaturas da Europa (GENTIL, 1930, p. 157). O teatro vicentino é fruto de influências diversas que podemos imaginar recíprocas, manifestas no estilo, nos gêneros, nas temáticas, nas personagens, e provavelmente também, mas isso é mais difícil de apreender, na própria organização do espetáculo, nas formas que este revestia e nos recursos técnicos então privilegiados. Parece ser no entanto com a cultura francesa que este tece ligações mais aprofundadas.

Numa tentativa para determinar se o teatro peninsular do século XVI era «autônomo», em resposta a Menéndez y Pelayo que contestava a influência do teatro francês, Georges le Gentil fundamenta o seu estudo no teatro vicentino. Após um primeiro artigo no qual analisa a forma como o Auto da Cananeia segue os passos dos «mistérios» franceses e «apresenta numerosos pontos de contacto com as Passions de Marcadé, d'Arnould Greban et de Jean Michel» (GENTIL, 1948), o investigador dedica um outro estudo aos «Temas de Gil Vicente nas moralidades, nas sotties e nas farsas francesas». Esse importante trabalho de cotejo dos textos permite-lhe estabelecer similitudes interessantes que deixam bem patente a marca do teatro francês. Não levarei mais avante esta exposição das conclusões de Georges le Gentil. Remeto para o artigo indicado. Para terminar, e antes de me dedicar ao assunto que constituirá verdadeiramente o meu contributo para a reflexão, voltarei à análise de Paul Teyssier. Conclui ele, em jeito de comparação entre o ascendente francês e o ascendente italiano:

[...] se excluirmos as réplicas «italianas» do Auto da Fama, não existe em toda a obra vicentina uma única citação, uma única reminiscência, uma única alusão que demonstre ter o autor conhecido a rica língua italiana. [...] Não assim no que diz respeito à França. [...] Toda uma série de observações convergem assim para uma conclusão geral. Gil Vicente pertencia a uma geração portuguesa que não tinha ainda recebido a influência italiana. Conhecia a Itália dos mercadores genoveses e venezianos de Lisboa, mas não a Itália de Dante e de Petrarca. Em contrapartida, a França ainda medieval das farsas, das sotties e das moralidades estava muito próxima dele, e não se pode 
imaginar de modo algum que a sua cultura lhe fosse totalmente estranha. (p. 346-347).

Esta conclusão parece justa. Proporei tão só uma pequena retificação: a proximidade em questão não se resume ao campo das farsas, das sotties e das moralidades. Por mais estranho que pareça, tem muito a ver com literatura de corte. Disso temos uma prova, edificante: a reelaboração da décima sétima novela das Cent nouvelles nouvelles numa das cenas que constituem Floresta de enganos, a última peça levada ao palco em 1536. É sabido que a novela constitui o substrato do passo em questão; Marques Braga menciona o fato, numa nota infrapaginal da sua edição das Obras completas de Gil Vicente. Ora, curiosamente, pouca atenção tem despertado esse « hipotexto », na terminologia de Genette. Transcrevo em anexo o texto, com uma proposta de tradução.

\section{De que se trata? O espírito "gaulês"}

Como o título o indica, este texto constitui a décima sétima de um conjunto de cem novelas. Segundo a primeira definição técnica, fomulada por Werner Söderhjelm, a novela,

forma narrativa breve, geralmente em prosa, apresenta uma situação geralmente colhida na vida de todos os dias e adstrita a um quadro estreito. O evento contado epiloga numa catástrofe inesperada ou surpreendente, o que significa que o elemento dramático assume um papel essencial na constituição da novela. Na origem, tudo está concentrado no efeito deste dito chistoso. (Jourda,1956, p. IX).

O gênero, que preexistia, inclusive em verso, através dos contos e dos fabliaux, ganha especial favor em França no século $\mathrm{XV}$, com a descoberta do Decamerón de Boccaccio, para verdadeiramente se afirmar no fim da Idade Média e durante boa parte do século XVI, favorecido pelo talento ímpar dos "excellents diseurs" - excelentes contadores. Boccaccio é o modelo: é o que se deduz do título do livro, a primeira coletânea de novelas da literatura francesa Les Cent nouvelles nouvelles, As Cem novelas novas, referência óbvia ao cânone, para o qual remete a dedicatória (JOURDA, p. 19); e é o que se deduz também do título de outra coletânea que igualmente evocarei, o Heptamerón de Margarida de Navarra, assim designado por só reunir setenta e duas novelas, devido à morte da rainha antes do acabamento da obra.

Com algumas variantes, e uma óbvia evolução que os rigores do tempo foram impondo, as Cent nouvelles nouvelles e o Heptamerón apresentam grandes similitudes, para além do espírito, da estrutura e da técnica, de que são devedores a Boccaccio. Uma delas, que particularmente me interessa, diz respeito aos contextos, de produção, e possivelmente de transmissão. Como se infere da dedicatória das Cent nouvelles nouvelles, o destinatário da obra é Filipe o Bom, duque de Borgonha, "Monsenhor", que ocupa um lugar 
de primeiro plano entre a assembleia, autêntica ou simulada, dos trinta e seis contadores-ouvintes, todos eles grandes senhores que Pierre Champion pôde identificar; quanto ao autor, se bem que incerto, era uma pessoa próxima da corte a quem o duque havia feito a encomenda da obra e que participava dessa mesma assembleia, quer se tratasse de Antoine de la Salle, a quem foi primeiramente atribuída a paternidade destas histórias, de Philippe de Loan ou ainda de Philippe Pot, por quem Pierre Champion finalmente se inclina (JOURDA, p. X). Toda uma representação dos grandes de alto estado, numa das cortes mais aparatosas, reunidos para contarem/ouvirem estas historietas, inventadas algumas, imitadas outras, outras ainda pura e simplesmente copiadas, num espírito que a dedicatória relembra:

Comme ainsi soit qu'entre les bons et prouffitables passe temps, le tresgracieux exercice de lecture et d'estude soit de grande et sumptueuse recommendation. (JOURDA, p. 19). ${ }^{4}$

Antes de entrar no texto, gostaria de fazer observar que, nesta nobre assembleia, faltam as mulheres. Esta constatação poderia levar a conclusões precipitadas, segundo as quais estes contos, e eventualmente encontros, se jogavam em terreno exclusivamente masculino. O Heptamerón de Margarida de Navarra traz, desse ponto de vista, um desmentido radical. $\mathrm{O}$ "autor" é uma autora, rainha letrada ainda mais. Reconheceram-se, além disso, sob a máscara dos pseudônimos, a rainha Margarida, os pais e outros familiares, na assembléia dos "praticantes", constituída à maneira de Boccacio por homens e mulheres. Trata-se indubitavelmente de um ambiente de corte, de que a sensibilidade feminina plenamente participa. E acrescentarei ainda que «a mui piedosa rainha» Margarida de Navarra deu como cenário a estas conversações uma abadia, Notre-Dame de Serrance; estabeleço aqui propositadamente um paralelo com «o mui piedoso rei» para o qual Gil Vicente fazia os seus aitos e lembro, em particular, que a Farsa de Inês Pereira foi representada no convento de Cristo, em Tomar.

Ora, da mesma forma que a farsa é um espectáculo por definição escabroso, que Corvin define como «uma metáfora sexual em acção» (CORVIN, p. 345), estas novelas inscrevem-se no âmbito dos «joyeux devis» - práticas jocosas. Cultivam o leviano, visam um riso solto, através de anedotas licenciosas, por vezes obscenas, dentro daquilo que se designa como "esprit gaulois", que nada tem de tipicamente gaulês mas é partilhado por toda a Europa e provavelmente por todas as culturas. Essas historietas picantes alimentam-se de um fundo comum e são fruto de uma

4 Tradução nossa: a fim que entre os bons e proveitosos passatempos, $\mathrm{o}$ mui gracioso exercício de leitura e de estudo seja de grande e sumptuosa recomendação. longa tradição. Nelas se encena todo um mundo de enganadores e de enganados, por vezes de enganadores enganados, segundo o preceito farcesco «jouer de la trompe», que joga com o duplo sentido de trompe, o instrumento musical, a trompa, e o verbo tromper, enganar; mulheres infiéis e maridos cucos, mulheres insaciáveis 
e maridos complacentes, clérigos devassos, juízes libidinosos e venais são as suas personagens de predilecção. Os temas repetem-se com variantes quando não migram pura e simplesmente de uma obra para outra, prática corrente nesses tempos em que o plágio não era banido. O fato de a sexagésima nona novela do Heptaméron retomar a décima sétima das Cent nouvelles nouvelles, como vim a descobrir ao longo desta investigação que exigiu um confronto de textos de várias literaturas, prova-o de forma flagrante; prova também, sem qualquer dúvida, o sucesso que esta novela especificamente conheceu; prova enfim aquilo que se afirma em todas estas situações convergentes: a existência de um público, sem fronteiras, que se comprazia nestes prazeres triviais, que eram também jogos de linguagem e arte consumada.

\section{O texto: a letra, o espírito}

A história, provavelmente contada ou lida num serão da corte do duque de Borgonha, por Monsenhor em pessoa, ou seja o próprio duque, traz para o primeiro plano um homem já de idade mas ainda verde, casado com uma mulher não só idosa como ele mas doentia, gasta pelos anos e pela «bela linhagem» que deu ao marido. Nada para estranhar: um casal convencional na literatura burlesca e no teatro em particular. O velho apresenta a dupla característica de ser libidinoso e de, na sua qualidade de Presidente do Tribunal de Contas, ocupar um cargo importante na sociedade, entre os mais elevados, o que lhe confere autoridade e poder. Beneficia este casal de uma situação invejável que lhe permite ter uma importante criadagem a seu serviço, incluindo, no pensamento do marido, serviços especiais a que ele efetivamente pretende. Põe o olho numa das mais belas moças. E temos aqui a personagem convencional do trio clássico. $\mathrm{O}$ velho persegue-a com as suas propostas, promete-lhe "todos os bens do mundo", manifesta-lhe «como está em seu poder favorecê-la de tal ou tal maneira». Sem resultado: a moça mostra-se indiferente às belas promessas do velho que muda então de argumentos e recorre à ameaça. Sem mais resultado:

[...] a boa moça, de grande integridade, querendo antes morrer do que perder a sua honra, não se deixou intimidar mas seguramente respondeu que podia ele dizer e agir a seu bel prazer, enquanto ela fosse viva nunca de mais perto a veria. (JOURDA, p. 76)

O senhor nem por isso deixa de lhe lançar olhares até que um dia, de madrugada, a ouve ocupada a peneirar farinha num quarto ao lado; certifica-se que a mulher continua no seu sono, «salta devagarinho da cama» e vai ter com ela para «levar a cabo o que lhe prometeu». Mas comete o erro de «parlamentar». A pretexto de certificar-se que a senhora continua dormindo e de que não correm o risco de que os venha surpreender nas suas 
ocupações, a camareira entrega-lhe a peneira, dá-lhe a beatilha e, deixando-o assim «enfarpelado», vai acordar a senhora a quem conta a história. Vendo o marido naquela estranha postura, a velha admoesta-o, perguntando: «Ah! Monsenhor e que é isto? E onde estão as vossas letras, as vossas grandes honras, as vossas ciências e discrições?», uma forma de sublinhar o desajuste na situação. Visivelmente pouco sensível a esse aspecto da questão, o marido dá uma resposta brutal, sem rodeios: «Na ponta do meu membro, senhora minha, foi aí que hoje concentrei tudo». Seguido pelo «sermão» da dama, volta furioso para o quarto, prepara-se, manda trazer a mula, «e vai-se ao palácio onde conta a sua aventura a vários gentis-homens que muito gargalharam com isso». Perdoa à criada, que ajudará a encontrar um bom partido.

Isto é a letra. Uma questão se coloca: o que é que, neste texto, poderá ter interessado o dramaturgo encarregado de organizar os divertimentos áulicos? Uma primeira resposta se impõe, com evidência: exatamente aquilo que interessou para o divertimento do duque de Borgonha e dos familiares da sua corte, por um lado, as mesmas razões que interessaram a rainha Margarida, pelo outro. E isso já tem mais a ver com o espírito.

Como muito bem observa Söderhjelm na sua definição, acima referida, «o elemento dramático assume um papel essencial na constituição da novela». A novela reúne todos os ingredientes da farsa, quer do ponto de vista técnico - concisão, vivacidade da acção, reviravoltas, desfecho rápido -, quer do ponto de vista temático - casal mal ajustado, baseado aqui na anormal intemperança do velho, tema que Gil Vicente já tinha levado à cena no Velho da Horta; assuntos tirados do quotidiano banal que culminam no trivial: relação dos senhores com aqueles que os servem, fainas desses mesmos servidores, neste caso a peneiração da farinha e o fabrico do pão; situação escabrosa; contexto de burla e inversão: senhor enganado pela servente, admoestado pela mulher. Em suma, tudo está efetivamente "concentrado no efeito da agudeza», que confirma o caráter obsceno da anedota através da palavra grosseira que o assume: «Na ponta do meu membro, senhora minha, foi aí que hoje concentrei tudo».

Em boa verdade, a grosseria já existia implicitamente no ato de peneirar a farinha que constitui o nó da acção. Essa dimensão, fundamental, de que a pátina do tempo nos privou, era conhecida de todos. É sobre ela que se elabora na realidade o essencial de um cômico que integra uma forte componente lúdica, fundada num discurso criptado, que por seu turno assenta no equívoco erótico.

\section{Modos de funcionamento: um público, um pacto, um código}

Como já tive oportunidade de desenvolver estes aspectos (KLEIMAN, 1995, 1996), limito-me a relembrar os elementos in- 
dispensáveis para uma compreensão aprofundada quer da novela quer da cena a que ela posteriormente dá corpo.

Regra n¹:

Para que haja jogo, tem que haver pelo menos dois parceiros, neste caso um escritor/narrador e um público; aquilo que se verifica nas três situações contempladas - Cent nouvelles nouvelles, Heptamerón, Floresta de Enganos - é que o jogo se faz no âmbito de um círculo mais ou menos fechado, de pessoas que evoluem no mesmo meio, que se conhecem, que se frequentam: ojogo instaura, ao mesmo tempo que a exige, uma forma de conivência entre os participantes, uma cumplicidade complexa que se exerce entre o escritor/ narrador e o público, mas também no seio do próprio público e, no que concerne especificamente ao teatro, entre a sala e a cena, ou seja entre o público e o(s) actor(es).

Regra n'2:

Tem que haver regras, conhecidas pelas duas partes. Ojogo consiste, e todos o sabem, na elaboração de uma história de duplo sentido, por parte do escritor/narrador, e da sua compreensão em todos os seus sentidos pelo público a quem se destina. Tudo repousa assim sobre o duplo processo da codificação, por um, e da decodificação, pelos outros, tendo cada qual conhecimento de que a chave se deve encontrar no terreno do obsceno, do erotismo de forma privilegiada.

O jogo do equívoco é um jogo de prática corrente na épo$\mathrm{ca}$, de que se encontram manifestações em todas as literaturas europeias. Sublinho em particular o fato de que os grands rhétoriqueurs da corte de Borgonha lhe atribuem um lugar eminente na hierarquia das virtudes poéticas e largamente o praticam, de forma muito mais complexa e diversificada que tem a ver também com a própria técnica. Aquilo que é visado, em todo o caso, são os efeitos de arte, os efeitos estéticos plein sonnants - plenamente soantes -, segundo a expressão de Paul Zumthor (1978, p. 269), poderíamos dizer espetaculares no registro do teatro. No campo específico do equívoco erótico, procura-se ainda um outro efeito, que se poderá definir como o principal objectivo: é obviamente o riso, cuja intensidade depende precisamente da virtuosidade do criador, do talento do público a penetrar o enigma, da perfeita adequação de um ao outro. E já se vê que, num caso como no outro, no da novela como no da farsa, aquilo a que se pretende é a um momento recreativo, de coesão social, entre pessoas do mesmo meio.

Quanto ao código, contentar-me-ei em citar aqui um passo do capítulo noventa e dois do livro V das Histórias de Heródoto, particularmente esclarecedor, já que comporta ao mesmo tempo o enigma e a sua elucidação: um texto precioso, por conseguinte. Detentora de um segredo que levou com ela para o reino dos mortos, Melissa, esposa de Periandro, exige para o divulgar que seja retificado o erro cometido pelo marido que, ao enterrá-la, omitiu 
queimar-lhe as roupas, condenando-a à nudez e ao frio. E, por intermédio dos emissários que foram consultar o oráculo, diz ao marido que «enfornou os seus pães no forno frio». A mensagem, hermética para os outros, é bem interpretada pelo seu destinatário, que fará o necessário para honrar a esposa. Heródoto, por seu lado, clarifica-lhe os termos de forma a que seja também acessível aos seus leitores: «[...]Periandro, - tendo reconhecido pelo sinal dado que podia ter confiança, porque se tinha unido a Melissa quando já estava morta $[\ldots ..] \gg$.

Este passo, muito distante da época contemplada, é rico em ensinamentos. Por um lado, confirma-nos que os modos criptográficos são, senão universais, pelo menos amplamente partilhados; pelo outro, oferece-nos uma chave para a decifração, que vem aliás confirmar algumas das minhas interpretações dos textos vicentinos e em particular a da cena da Forneiro e do Ferreiro do Triunfo do Inverno e do Verão (KLEIMAN, 1995). Todo o interesse reside no fato de que esta chave é irrefutável, já que o código, situação raríssima, é acompanhado pelos meios da sua decodificação, diretamente fornecidos por quem codificou. Tal como se nos apresenta, explicado por Heródoto, o processo joga sobre dois planos essenciais: o de um segredo partilhado, fundado numa experiência comum e o de uma cumplicidade preexistente à situação evocada, fundamentada nos laços que ligam Melissa e Periandro, a partir da qual procuram a significação premeditada. É essa mesma cumplicidade, assente no código partilhado e na expectativa suscitada, que permite que o acontecimento - leitura, narração, ou espetáculo - lúdico possa plenamente perfazer-se, no âmbito particular daquilo que Paul Zumthor chama o «jogo da corte», a corte dos reis, lugar teatral por excelência (p. 39). Quanto ao código, observa-se que a elucidação global da misteriosa resposta de Melissa basta para garantir a compreensão da mensagem; acontece porém que ela permite igualmente a identificação do sentido oculto afetado a cada um dos termos que compõem esta resposta. Torna-se assim possível reconstruir o princípio de equivalência seguinte :

- «pães» : órgão sexual masculino

- «forno» : órgão sexual feminino

- «enfornar» : introduzir o pênis na vagina e por conseguinte copular

- «frio» : marcador de morte (neste caso, marcador de uma relação necrófila).

Em muitos aspectos, a hermenêutica destes textos, e nomeadamente a do teatro vicentino, tornou-se para nós senão uma ciência do oráculo, pelo menos uma ciência da adivinhação. Para nós, mas não para as gentes da época, acostumadas a estes exercí- 
cios, conhecedoras das regras globais de elaboração do discurso, peritas nesta ciência secreta da linguagem que exige de nós uma reapropriação dos códigos que a regem.

O duplo discurso elabora-se simultaneamente a dois níveis, de forma a produzir um discurso de aparência, inocente, imediatamente inteligível por todos e que muitas vezes joga com o ingênuo, e um discurso malicioso, por vezes obsceno, que sorrateiramente se dissimula sob a máscara do equívoco e de que não estou longe de pensar que é precisamente ele que preside à elaboração do texto. O alicerce do edifício é a metáfora sexual. Uma das lições a reter para chegar a uma compreensão mínima e poder progredir na apropriação é que aquilo que preside à elaboração das imagens sexuais é o pensamento analógico. Para me manter ao nível dos termos do texto que vamos agora abordar, a vara é evocadora do sexo masculino, o alguidar e a peneira do sexo feminino, a farinha do esperma, e o ato de peneirar da copulação. Isto é uma linha geral; na realidade as coisas não são assim tão simples. $O$ pão, por exemplo, poderá dar lugar a representações diferentes, segundo o caso: sobre o comprido, fará pensar no membro viril, sobre o redondo tanto poderá figurar o órgão sexual feminino como as nádegas. Em suma, o sentido não é dado; tem que ser conquistado, de alta luta.

\section{A adaptação da novela : a cena do Justiça Maior e da Moça, em Floresta de Enganos}

O episódio de Floresta de Enganos que se inspira da novela, retoma os seus diversos ingredientes, com algumas variantes interessantes. Mantém-se o mesmo número de personagens, três, aos quais se atribuem papéis semelhantes aos do original. Como o da novela, o protagonista da farsa ocupa um cargo de primeiro plano, no seio de uma das mais altas instâncias, com esta diferença que Gil Vicente lhe atribui uma dignidade mais importante ainda, fazendo dele o segundo do reino:

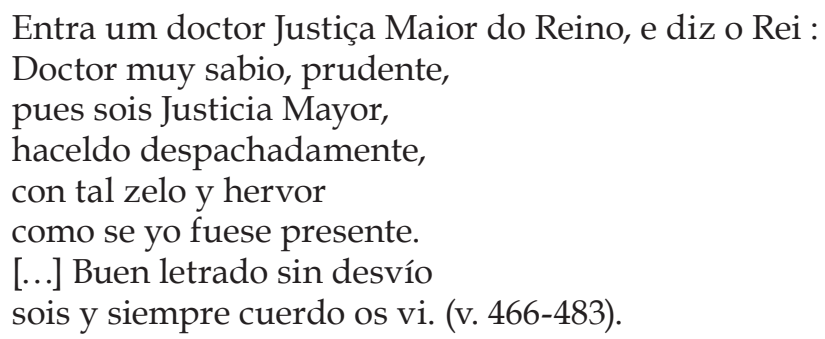

Como ele, é velho,

Ya hize sesenta y seis,

ya mi tiempo es pasado. (V. 512-513), 
lúbrico

Quem tal quer

nam havia de ter molher,

e fermosa como a vossa. (528-530),

e serve-se da sua posição para comprar os favores a que pretende:

Yo daré, juro a Dios,

la sentencia en vueso hecho ;

y aunque no tengais derecho,

todo ello saldrá por vos,

y hareis vueso provecho. (543-547).

O dramaturgo acentua no entanto a gravidade das faltas da personagem que não se limita a exercer uma pressão sobre a sua vítima mas se revela corrupto no exercício da sua função.

Da mesma forma, a servente encontra o seu duplo na farsa. Ambas são dotadas das mesmas qualidades: juventude, beleza física, integridade, audácia, fineza, mas Gil Vicente reforça, aqui também, os dotes cujas virtualidades teatrais são mais certas. Se ambas são espertas, a segunda é mais finória, ardilosa até, não exatamente, como a outra, obrigada a enganar para se defender, mas jubilosa pela partida que pregou e claramente adepta do jogo de palavras obsceno. Ultrapassa largamente em talentos o seu modelo, o que não é de admirar, já que não há, entre ela e o Justiça Maior uma relação de hierarquia, como ocorre na novela.

Uma diferença importante intervém no caso da terceira personagem. A mulher, que existe, como se sabe pela réplica moralizadora da Moça, não aparece em cena. É teatralmente substituída pela Velha, avó da Moça. A analogia é no entanto claramente marcado pela reposição das admoestações da esposa, reconhecíveis nas referências jurídico-culturais que a Velha introduz no meio das obscenidades proferidas:

Dizede, Doutor da má hora

e falai-me per latim:

que diz o Bártolo aqui ?

[...] No Baldo acharíeis, Doutor,

essa negra amassadura,

ou na sagrada Escritura? (671-692).

Haverá provavelmente duas boas razões para que essa substituição tenha sido operada. Por um lado, a lubricidade do Justiça Maior escapa ao meio privado para sair a público; por outro lado, o confronto com a Velha, grosseira, permite explorar a situação de desajuste na qual o Justiça Maior se encontra envolvido, por responsabilidade própria. É essa discrepância que o espetáculo sublinha e explora, não só na escolha das personagens como também no desenrolar da intriga. O episódio representado é, nas 
suas grandes linhas, muito semelhante ao original: retrato do protagonista, moral desta vez; chegada da Moça e propostas do juiz que contradizem o retrato; visita do juiz à Moça; preparação do juiz pela Moça para a cena de peneiração; chegada da Velha cujas zombarias, juntamente com as mofas da Moça terão por efeito fazer debandar o velho libidinoso. Gil Vicente conserva a trama, mas introduz modificações significativas, que vão no sentido de uma exploração simultânea, e até mesmo em interdependência, do lúdico, do cômico e da sátira. A cena da peneiração constituirá o ponto chave dessa tripla aliança.

A cena em questão é visivelmente um empréstimo, quase literal, da novela. Como no original, o seu cômico repousa em grande parte na ambiguidade do termo beluter/ «peneirar», elaborada, como se disse, a partir da analogia entre os movimentos ligados ao «peneirar» e os movimentos ligados ao copular. Mas intervém aqui uma diferença fundamental: o diálogo e o jogo dos atores oferecem recursos que o caráter breve, narrativo, da novela não permite, se bem que se possa muito bem imaginar um acompanhamento gestual no âmbito de uma leitura ou narração coletiva. No episódio de Floresta de Enganos, o jogo não se restringe a uma ideia, mas é desenvolvido ao longo das réplicas, a partir dessa ideia; para além disso, se é indubitável que é ainda essa ideia que está na origem do processo lúdico de elaboração do discurso «equivocado», o fato é que o jogo não fica por aí, mas contamina todo o diálogo. Tudo, a partir daí, remete para a lubricidade de uma Justiça Maior, tanto mais em situação de discrepância que os seus pobres conhecimentos em matéria de amor não estão à altura das suas ambições. Note-se de passagem que ele é Espanhol e elas Portuguesas.

\section{Alguns elementos para uma interpretação:}

Após ouvir as propostas desonestas do Juiz, a Moça premedita a burla. Di-lo nestes termos, que introduzem aquilo que em francês se designa por métaphore filée, metáfora continuada, e que vai por conseguinte desenrolar-se segundo a linha, aqui sugerida, da preparação do pão, de que a peneiração não é senão uma etapa:

Oh como hei-d'enganar

hum doutor que se enganou!

Alguidar, ora vem cá,

e faremos o formento. (560-563).

Trata-se de fazer os preparativos para excitar - «formento» - o juiz. $\mathrm{O}$ «alguidar» - órgão sexual feminino -, recipiente redondo, que recolhe a «farinha» - esperma e secreções vaginais -, onde se faz a «amassadura» - coito - antes de levar ao «forno» - órgão sexual feminino. A Moça apresenta assim a operação, nas maliciosas lições que dá ao Juiz: 
Hui, faze asinha o formento,

e amassarás de madrugada,

estará o forno milhor (649-651).

que as recebe como lições de peneiração. São na realidade magistrais lições de sexualidade :

Não peneirais bem, Doutor.

Qeuro-vos dar uma lição.

Tomai aqui com esta mão

Ora andai assi ao redor (600-603).

Este exemplo ilustra particularmente as potencialidades dramáticas que o episódio central da novela oferece e que, na cena áulica da cidade de Évora, são grandiosamente aproveitadas, ao ponto de, no palco, perante $\mathrm{o}$ «muito alto e poderoso rei D. João o terceiro deste nome», a gestualidade do peneirar se confundir com a do copular. A situação não deixa de ser picante, sabendo que os ensinamentos são ministrados pela Moça pretensamente ingênua, ao velho frustrado de amores que reconhece por si próprio as suas deficiências na matéria :

\section{Paciencia \\ porque juro en mi conciencia \\ que este texto yo no lo entiendo. \\ [...] Estas vueltas no sé yo. \\ [...] que no se aprende en Paris \\ este lavor en que estó. (614-623).}

A metáfora continuada integra, além disso, a figura tradicional da padeira, que não posso aprofundar aqui. Bastará dizer que, para além de estar ligada à farinha e ao pão, o que a expõe aos jogos do subentendido erótico, a personagem da padeira tinha uma reputação de mulher de maus costumes e era identificada à «puta vieja», ou seja à personagem mal afamada da alcoviteira (KLEIMAN, 1995). A assimilação do juiz à padeira, nos versos 670 e 689, não é um simples dito espirituoso mas um verdadeiro insulto: ao tomar a aparência da padeira, o juiz encontra-se investido de todos os vícios que ela encarna. É o que a Velha sublinha, de várias formas, mas em particular através da polissemia dos termos «amassadura» (690-692), e sobretudo «farinha», numa réplica saborosa onde associa o peneirar, o copular e o julgar, pondo em causa a honestidade dos julgamentos do juiz e zombando dele ao insinuar que acaba de «peneirar» com ela:

[...] e não abasta a farinha que fazedes no julgar, senão virdes peneirar hũa pouca que aqui tinha no fundo do alguidar? (704-708).

\section{As conclusões}

Voltando agora às questões iniciais, respeitantes à cultura de Gil Vicente, às fontes em que o poeta dramaturgo bebeu, às 
influências francesas, pode-se concluir, sem a menor dúvida, que o texto da décima sétima novela constitui o hipotexto a partir do qual se elaborou a cena que põe em presença Justiça Maior e a Moça, em Floresta de enganos. A peça por si deve muito às letras e ao teatro franceses: deve-lhes em particular o tema geral, do enganador enganado, que articula diferentes quadros que a compõem, e o diálogo inicial. Mas essa dívida, essencialmente de caráter temático ou contextual, é demasiado imprecisa para poder ser realmente avaliada. No caso da novela não é bem assim. As semelhanças são múltiplas e manifestas. Não se limitam a uma temática, mas concernem factos precisos, personagens afins, com funções, senão idênticas, mais ou menos equivalentes, um desenrolar da ação análogo, uma situação de inversão inesperada, um episódio central idêntico, tratado sobre o modo da aequivocatio e culminando no chistoso ou no burlesco, um desfecho cômico em desfavor do personagem principal. A estes argumentos poderia eventualmente opôr-se o de que os temas e as situações são tópicos que pertencem a uma longa tradição jocosa. As metáforas em torno do pão, da farinha, da peneiração, da amassadura são legião, em França, na península e alhures. De uma certa forma, no seu tratamento geral da cena, Gil Vicente é também tributário de outras culturas. Sucede porém que ele aqui não imita simplesmente uma maneira, não produz uma imagem qualquer, da sua invenção, sobre o peneirar: faz, a bem dizer, uma transposição para o palco da situação narrada na novela, que o diálogo enriquece no sentido do jogo do equívoco, mas que é a mesma. E há mais: não pode ser por acaso que as réplicas da Velha vêm assim tão rigorosamente ao encontro das admoestações da esposa. É évidente que Gil Vicente tinha um conhecimento profundo desta novela. Como? Essa é a questão. A precisão na imitação, e nomeadamente no que respeita às réplicas referidas, que implicam uma compreensão linguística, pode levar a crer que Gil Vicente conhecia rudimentos da língua francesa, como opina Paul Teyssier. Não é de todo impossível que ele tenha lido o texto. Mas nada no-lo confirma. A história era conhecida, não nas suas grandes linhas mas de forma extremamente precisa, como atestam as diversas reescritas a que se prestou, em Portugal, para o palco vicentino, em França e na Itália, num período mais tardio, através da pena de Margarida de Navarra e de Giovambattista Giraldi Cinzio (Gli Ecatommiti, 1563). O jogo de influências era grande. Os textos circulavam, de corte em corte, e não é impossível também que essa circulação se tenha apropriado de narrações ou leituras coletivas, em saraus de «joyeux devis», à medida daqueles que reuniam a corte de Borgonha em torno de Filipe o Bom, num momento lúdico, de sã "recreação", de coesão social também. Quanto a isso, só podemos fazer conjeturas.

O que não oferece dúvida é que, de um texto saboroso, ao gosto da época, do qual guardou o espírito e boa parte da 
5 Tradução nossa: Que dizeis, senhoras, desta mulher? Não foi bem avisada, de se divertir com o passatempo do marido? - Não é passatempo, disse Saffredent, para o marido, ter falhado no seu negócio. - Imagino, disse Ennasuite, que teria tido maior prazer a rir com a esposa, que a ir-se matar, naquela idade, com a sua camareira). (JOURDA, p. 1087). matéria, Gil Vicente fez um espetáculo mais saboroso ainda, ao qual imprimiu a marca do seu gênio criador, de que o diálogo é o principal veiculador. Aproveitando a situação cômica, leva-a até ao excesso e faz despoletar o riso pela acumulação burlesca, numa demonstração magistral da sua ciência da aequivocatio, de que também poderá, pelo menos no espírito, ser devedor a essa mesma corte de Borgonha, com a qual Portugal mantinha relações privilegiadas desde o casamento do duque com a Princesa Isabel. Os poetas borgonheses praticavam com maestria esta arte que concebiam como ciência: "Qui veult pratiquer la science choisisse plaisants équivoques» (Quem quer praticar a ciência, escolha equívocos jocosos) era o seu preceito, formulado por Jean Molinet, que nos esclarece assim sobre os gostos das elites de corte e as práticas de uma época. $\mathrm{O}$ texto imitado foi obviamente escolhido por Gil Vicente por essa razão essencial, pelas suas virtualidades teatrais e artísticas, levadas aos seus extremos burlescos, en conformidade com as expetativas do público. Mas desse burlesco excessivo, o dramaturgo fez aqui um instrumento da sátira. Não é sempre o que sucede no seu teatro, contrariamente às interpretações que têm sido feitas. Note-se que a sátira não constitui uma preocupação para a novela. Não há moral. A história termina num gargalhar geral, aquele riso carnavalesco que os franceses dizem gras que é a aposta principal, que tudo justifica; os tempos eram licenciosos. No texto de Margarida de Navarra, quase um século depois, verifica-se uma evolução. Os tempos estão a mudar. Se bem que não desdenhem o escabroso, muitas vezes em esquisita conciliação com o cortês, as novelas são enquadradas por comentários e reflexões, por vezes explicativos, por vezes ainda de caráter moralizante, como na sexagésima nona. Após um final feliz - «le tout s'appaisa au contentement des partyes; et puis vesquirent ensemble sans querelles» (tudo se apaziguou para grande contentamento das partes; e daí em diante viveram juntos sem querelas), inicia-se um debate sobre as relações do casal e as reações da esposa

Que dictes-vous, mes dames, de ceste femme? N'estoit-elle pas bien saige de passer tout son temps du passetemps de son mary? - Ce n'est pas passetemps, dist Saffredent, pour le mary, d'avoir failly à son entreprinse. - Je croy, dit Ennasuite, qu'il eut plus de plaisir de rire avecq sa femme, que de se aller tuer, en l'aage où il estoit, avecq sa chamberiere. ${ }^{5}$

Histórias e debates que os tempos passados prezavam, com os quais as farsas sustentavam o riso, levando ao palco os vícios da humanidade, que não poupam inclusive os "grandes de alto estado"; assuntos ainda de uma grande atualidade, suscetíveis de uma mobilização e de uma teatralização que vai além das fronteiras, provando se necessário fosse o quanto a literatura do passado constitui uma forma de dizer o que somos no presente. 


\begin{abstract}
Falling within a wider reflection and focused on the rereadings of the past and the present, as well as on the cultures among frontiers, this article has as its central theme the Vicentian theatre, a paradigm of the culture of the other-foreigner or predecessor-, highly valued in the past. During the first three decades of the XVI century, between 1502 and 1536, period of visible opening and interchange between courts, with their retinue of artists, Gil Vicente presided over the entertainment of a bilingual and bicultural court. Owing largely to the neighbouring literature, his theatre takes into account other influences. Among them, the French one occupies a relevant position, either in the recovery of themes, characters or linguistic elements, or in the imitation of genres and forms. The present study is not limited to the observation of an influence; it explores the text and the very mechanisms of the show to evaluate the form through which this theatre interacts with other European cultures that nurture it. We propose a confrontation between a text- a scene with the presence of the Judge and the Girl, from Floresta de enganos- and its "hypotext"- one of the short stories from the book Cent nouvelles, offered to the Duque of Burgundy around 1461-1462. Another aim is to shed light on domains we know very little about, such as the one which refers to the culture of the playwright and poet, very badly evaluated by the serious interpretation of a largely manipulated and excessively manipulative text.
\end{abstract}

Keywords: Vicentian theater; French influence; culture of misconception

\title{
REFERÊNCIAS
}

CORVIN, Michel. Dictionnaire Encyclopédique du Théâtre. Paris: Bordas, 1995.

JOURDA, Pierre, Conteurs français du XVI ${ }^{\mathrm{e}}$ siècle. Paris: La Pléiade, 1956. (Les Cent nouvelles nouvelles, (p. 1-358) ; L’Heptaméron (p. 699-1129).

KLEIMAN, Olinda. «Gil Vicente: o texto na sua teatralidade, a letra, a carne, o espírito». Homenagem ao professor Stephen Reckert. Centro de Estudos de Teatro da Universidade de Lisboa, Lisboa: Imprensa Nacional - Casa da Moeda, p. 587-601, 2011. 
- «Une herméneutique du théâtre vicentin : un art de la divination ?». Florence Lévi (éd), Sigila, n²6, Paris, Gris-France, p. 161-171, 2010.

. «Des Indes, de leurs trésors et de leurs épices : La Farce de l'Inde, de Gil Vicente, ou l'Histoire manipulée». L'Histoire irrespectueuse. Humour, dérision, caricature, vol. Humour et sarcasme dans la fiction historique - Espagne, Portugal, Amérique latine -, textos reunidos por Mercedes Blanco, Lille, Université Charles de Gaulle, Travaux et recherches, p. 25-44, 2004.

"Côté cour, côté rue.... côté couvent : La Farce d'Inès Pereira de Gil Vicente». Théâtre de cour, théâtre de ville, théâtre de rue. Textes édités par Robert Horville, Olinda Kleiman, Godeleine Logez, U.L.3, Travaux et recherches, p.163-175, 2001.

- «La réélaboration de la $17^{\mathrm{e}}$ des Cent nouvelles nouvelles dans Floresta de Enganos de Gil Vicente ». D'un genre à l'autre, Les langues néo-latines, Paris, p. 33-56, 1996.

.Maria Parda: le vin des étoiles», Quadrant, Université de Montpellier, n 13, p. 5-26, déc. 1996.

. «De la boulangère et du forgeron : un exemple de langage érotique dans l'œuvre de Gil Vicente». Quadrant, Université de Montpellier, n 12, p. 31-53, dez. 1995.

GENTIL Georges Le. «La Cananeia de Gil Vicente et les mystères français». Mélanges dédiés à la mémoire de Georges Cirot, Bulletin Hispanique, Bordeaux, Geret et fils, p. 353-369, 1949.

. «Les thèmes de Gil Vicente dans les moralités, sotties et farses françaises». Hommage à Ernest Martinenche, Études Hispaniques et Américaines. Paris : éditions d'Artrey, 1930, p. 156-174. Les Cent nouvelles nouvelles. (In JOURDA).

NAVARRE, Marguerite de. L'Heptamerón. (In JOURDA).

SAETTA-COTTONE, Rossella. Aristofane e la poetica dell' ingiuria. Per una introduzione alla loidoría comica. Roma, Carocci, 2005.

TEYSSIER, Paul. A Lingua de Gil Vicente. Lisboa : Imprensa Nacional - Casa da Moeda, 2005.

. «Essai d'explication du passage en "picard" de l'Auto das

Fadas de Gil Vicente». Bulletin des Études Portugaises et de l'Institut Français au Portugal, Lisboa, XVII, p. 223-245, 1953.

VICENTE, GIL. Copilaçam de todalas obras de Gil Vicente. Ed. fac-similada da edição de 1562. Lisboa: Biblioteca Nacional, 1928. ZUMTHOR, Paul. Le Masque et la lumière, la poétique des grands rhétoriqueurs. Paris: Seuil, 1978. 


\section{ANEXO \\ LA DIX SEPTIESME NOUVELLE}

\section{PAR MONSEIGNEUR}

N'aguères que a Paris presidoit en la chambre des comptes ung grand clerc chevalier assez sur eage, mais tres joyeux et plaisant homme estoit, tant en sa maniere d'estre comme en ses devises, ou qu'il les adressast, ou aux hommes ou aux femmes. Ce bon seigneur avoit femme espousée desja ancienne et maladive, dont il avoit belle lignée. Et entre aultres damoiselles, chambrieres et servantes de son hostel, celle ou nature avoit mis son entente de la faire tresbelle, meschine estoit, faisant le mesnage commun, comme les litz, le pain et aultres telz affaires. Monseigneur, qui ne jeunoit jour de l'amoureux mestier tants qu'il trouvast rencontre, ne cela gueres a la belle meschine le grand bien qu'il luy veult, et luy va faire ung grans prologue d'amoureux assaulx que incessamment amour pour elle luy envoye ; continue ainsi ce propos, promettant tous les biens du monde, monstrant comme il est bien en luy de luy faire tant en telle maniere, en telle et en telle. Et qui oyoit le chevalier, jamais tant d'eur n'advint a la meschine que de luy accorder son amour. La belle meschine, bonne et sage, ne fut pas si beste que aux gracieux motz de son maistre (ne) baillast response en rien a son avantage, mais s'excusa si gracieusement que monseigneur en son courage tresbien l'en prise, combien qu'il amast mieulx qu'elle tenist aultre chemin. Motz rigoreux vindrent en jeu par la bouche de monseigneur, quand il perceust que par doulceur il ne fasoit rien ; mais la tresbonne fille et entiere, amant plus cher morir que perdre son honneur, ne s'en effraya gueres, ains asseurement respondit, dye et face ce qu'il luy plaist, mais jour qu'elle vive de plus près ne luy sera. Monseigneur, qui la voit ahurtée en ceste opinion, après ung gracieux adieu, laisse ne sçay quans jours ce gracieux pourchaz de la bouche tant seulement; mais regards et aultres petiz signes ne luy coustoyent gueres, qui trop estoient a la fille ennuyeux. Et si elle ne doubtast mettre male paix entre monseigneur et madame, il ne luy chauldroit guere de la desloyaulté de monseigneur ; mais au fort elle conclud se deceler au plus tard qu'elle pourra. La devocion que monseigneur avoit aux sains de sa meschine de jour en jour croissoit, et ne luy souffisit pas de l'amer et servir en cueur seullement, mais d'oroison, comme il a fait cy devant, la veult arriere reservir. Si vient a elle, et de plus belle recommença sa harengue en la fasson comme dessus, laquelle il confermoit par cent mille sermens et autant de promesses. Pour abreger, rien ne luy vault. Il ne peut obtenir ung tout seul mot, et encores mains de semblant qu['elle] luy baille quelque pou d'espoir de jamais non pervenir a ses attainctes. Et en ce point se partit ; mais il n'oblya pas a dire a ce partir que, s'il la rencontre en quelque lieu marchant, ou elle obeyra, ou elle fera pis. La meschine gueres ne s'en effraya, et sans plus y gueres penser va besoigner a sa cuisine ou aultre part. Ne sçay quans jours après, par ung lundi matin, la belle meschine, pour faire des pastez, thamisoit de la fleur. Or devez vous savoir que la chambrette ou se faisoit ce mestier n'estoit guere loing de la chambre de monseigneur, et qu'il oyoit tresbien le bruyt et la noise qui se faisoit a ce coup. Savoit aussi tresbien que c'estoit sa chambriere qui de thamis jouoit ; si s'avisa qu'elle n'aroit pas seule ceste peine, mais luy vouldroit aider, voire et fera au surplus ce qu'il luy a bien promis, car jamais mieulx a point ne la pourroit trouver. Dit aussy en soy mesmes : «Quelque refus que de la bouche elle mayt fait, si en cheviray je bien si je la puis a graux tenir ». Il regarda que bien matin encores estoit, et que madame n'estoit pas encores eveillée ; il sault tout doulcement hors de son lit, a tout son couvre-chef de nuyt, et prend sa robe longue et ses botines, 
et descend de sa chambre si celeement qu'il fut dedans la chambrette ou la meschine tamisoit qu'elle oncques n'en sceut rien tant qu'elle le vit tout dedans. Qui fut bien esbahie, ce fut la pouvre chambriere, qui a pou trembloit, tant estoit asserrée, doubtant que monseigneur ne luy ostast ce que jamais rendre ne luy saroit. Monseigneur, qui la voit effraiée, sans plus parler luy baille ung fier assault, et tant fist en pou d'heure qu'il avoit la place emportée s'il n'eust esté content de parlamenter. Si luy va dire la fille : « Helas! monseigneur, je vous cry mercy, je me rends à vous ; ma vie et mon honneur sont en vostre main, aiés pitié de moy. - Je ne scay quel honneur, dit monseigneur, qui treseschaufé et esprins estoit ; vous passerez par la». Et a ce coup recommence l'assault plus fier que devant. La fille, voyant qu'eschapper ne pouvoit, s'advisa d'ung bon tour, et dist : « Monseigneur, j'ayme mieulx vous rendre ma place par amours que par force; donnez fin, s'il vous plaist, aux durs assaulx que me livrez, et je feray tout ce qu'il vous plaira. - J'en suis content, dist monseigneur ; mais creez que aultrement vous n'eschapperez. - D'une chose vous requier, dist lors la fille. Monseigneur, je doubte beaucoup que madame ne vous oye et ait oy, et s'elle venoit d'adventure, et droit cy vous trouvast, je seroie femme perdue, car du mains elle me feroit batre ou tuer. - Elle n'a garde de venir, non, dit monseigneur ; elle dort au plus fort. - Helas ! monseigneur, je la doubte tant que je n'en scay estre asseurée. Si vous prie et requier, pour la paix de mon cueur et plus grande seureté de nostre besoigne, que vous me laissez aller veoir s'elle dort ou qu'elle fait. - Nostre Dame, tu ne retournerois pas, dit monseigneur. - Si feray, par mon serment, dit elle, trestout tantost. - Or je le veil ! dit il, avance toy. - Ha ! monseigneur, si vous voulez bien faire, dit elle, vous prendrez ce thamis et besoignerez comme je faisoie, affin d'aventure, si madame est esveillée, qu'elle oye la noise que j'ay devant le jour encommancée. - Or monstre ça, je feray bon devoir, et ne demoure gueres. Nenny, monseigneur ; tenez aussi ce buleteau, dit elle, sur vostre teste, vous semblerez tout a bon escient estre une femme. - Or ça, dit il, [de] pardieu ça ». Il fut affublé de ce buleteau, et si commence a thamiser, que c'estoit belle chose tant bien luy siet. Et entretant la chambriere monta en la chambre et esveilla madame, et luy compta comment monseigneur par cy devant d'amours l'avoit priée et qu'il l'avoit assaillie a ceste heure ou el tamisoit. «Et s'il vous plaist veoir comment j'en suis eschappée et en quel point il est, venez en bas, vous le verrez ». Madame tout a cop se leve, et prend sa robe de nuyt, et fut tantost devant l'huys de la chambre ou monseigneur tamisoit diligemment. Et quand elle le voit en cet estat, et affublé du buleteau, elle luy va dire : « Ha ! monseigneur, et qu'est ceçy? et ou sont voz lectres, voz grands honeurs, voz sciences et discrecions ? » Et monseigneur, qui deceu se voit, respondit tout subitement : " Au bout de mon vit, dame, la ay je tout amassé aujourd'uy ». Lors tres marry et courroucé sur la meschine se desarma du thamis et du buleteau, et en sa chambre remonte. Et madame le suyt, qui son preschement recommence, dont monseigneur ne tient gueres de compte. Quant il fut prest, il manda sa mule, et au palais s'en va, ou il compta son adventure a pluseurs gens de bien qui en risirent bien fort. Et me dist l'on depuis, quelque courroux que le seigneur eust de prinsault a sa belle meschine, si l'ayda il depuis de sa parolle et de sa chevance a marier.

Les Cent nouvelles nouvelles. In Conteurs français du XVI ${ }^{e}$ siècle, édition établie et annotée par Pierre Jourda, Paris: Gallimard, Bibliothèque de la Pléïade, 1956, p. 76-79. 


\section{A décima sétima novela por Monsenhor}

Em tempos não muito remotos, era o Tribunal de Contas em Paris presidido por um fidalgo cavaleiro, homem sábio, de idade assaz avançada, porém jovial e de comércio agradável, quer na sua maneira de ser quer na sua prática, fosse homem ou mulher o seu interlocutor. Havia este excelente senhor desposado uma mulher já anciã e de temperamento doentio que lhe dera uma bela linhagem. E de entre todas as donzelas, camareiras e criadas do seu palacete, aquela que a Natureza havia acordado fazer moça de grande formosura era uma servente que se dedicava às tarefas comuns, como fazer as camas, o pão e outras semelhantes obrigações. Monsenhor que nenhum dia jejuava das fainas amorosas por pouco que se lhe oferecesse a oportunidade de um encontro, não ocultou à bela servente o grande bem que lhe quer e vai acometê-la com um belo prólogo de amorosos assaltos que continuamente amor por ela lhe envia; e assim prossegue o seu colóquio, prometendo oferecer-lhe todos os bens do mundo, manifestando-lhe como está em seu poder favorecê-la de tal ou tal maneira. E para quem ouvia o nobre cavaleiro, nunca tão feliz oportunidade se oferecera à criada como esta de lhe conceder o seu amor. A bela criada, boa e prudente, não foi tão néscia que reservasse às graciosas palavras de seu mestre uma resposta vantajosa mas apresentou tão graciosas desculpas que, no seu íntimo, Monsenhor sentiu por ela grande estima, se bem que muito mais lhe aprouvera que ela houvesse escolhido outro caminho. Palavras rigorosas irromperam da boca de Monsenhor quando se apercebeu de que pela doçura nada resolvia; porém a boa moça, de grande integridade, querendo antes morrer do que perder a sua honra, não se deixou intimidar mas seguramente respondeu que podia ele dizer e agir a seu bel prazer, enquanto ela fosse viva nunca de mais perto a veria. Monsenhor, que a vê acérrima na sua opinião, despedindo-se graciosamente, deixa-se durante não sei quantos dias daquela galante perseguição, mas pela boca tão somente, já que não era parco de olhares nem de outros pequenos sinais, para a moça mui fastidiosos. E não fora o receio de introduzir a discórdia no casal, pouco lhe importaria a deslealdade de Monsenhor; mas finalmente resolveu não se descobrir senão o mais tarde possível. A devoção de Monsenhor pelo santo altar da servente ia crescendo dia após dia e não lhe bastava amá-la e servi-la do fundo secreto do coração, mas com as devidas orações a quer voltar a servir, como já fizera. Vai-se a ela e toca a recomeçar a sua arenga com mais fervor ainda que antes, confirmando o prometido com cem mil juramentos e outras tantas promessas. Enfim, de nada lhe vale. Dela não consegue obter uma única palavra e menos ainda que deixe transparecer a mais pequena sombra de uma possibilidade de um dia poder ver realizadas as suas esperanças. E neste ponto se foi; mas, ao partir, não deixou de dizer que, se em qualquer parte os seus caminhos se vierem a cruzar, ou ela obedece, ou então pior para ela. A moça, pouco impressionada, e sem mais pensar no assunto, lá se vai aos seus afazeres, na cozinha ou alhures. Não sei quantos dias depois, uma segunda-feira pela manhã, estava a bela servente atarefada a peneirar farinha para fazer pastéis. Ora, convém que saibais que a saleta onde se entregava a esta ocupação não se encontrava muito longe do quarto de Monsenhor, que ouvia perfeitamente o ruído e o bulício que por ali havia. E também sabia muito bem que era a sua camareira que lá estava a fazer a dança da peneira; resolveu então que não a deixaria penar assim sozinha, mas que a queria ajudar e levar a cabo o que lhe prometeu, e até mais do que isso, porque nunca em melhor condição a poderia encontrar. E disse para consigo: «Se bem que de sua boca só tenham vindo recusas, eu me encarrego de a domar se a apanho a jeito». Certificou-se que era ainda de manhãzinha e que a senhora não estava acordada; salta devagarinho da cama, com o barrete-de-dormir na cabeça, 
pega no vestido de noite e nas botinas e desce do quarto tão suavemente que apareceu na saleta onde a criada peneirava sem que ela se apercebesse de nada até o ver mesmo lá dentro. Quem ficou bem espantada, foi a pobre camareira, que se pôs quase a tremer de tão aterrada que estava, receosa que Monsenhor lhe tirasse o que jamais lhe poderia devolver. Ao vê-la assim amedrontada, Monsenhor, sem uma palavra manda-lhe um assalto fogoso e tanto fez em pouco tempo que poderia ter conquistado a praça não fora seu prazer parlamentar. Diz então a moça: «Ai, pobre de mim! Monsenhor, misericórdia vos rogo, rendo-me à vós; a minha vida e a minha honra estão entre as vossas mãos, tende piedade de mim. - Não sei que honra, disse Monsenhor que muito aceso e apaixonado se sentia; por aqui haveis de passar». E eis que renova o assalto com mais ímpeto ainda do que antes. A Moça, vendo que não podia escapar, lembrou-se de lhe pregar uma boa partida e disse: «Monsenhor, prefiro render-me a vós por amor que por força; ponde fim, por favor, aos duros assaltos com que me arremeteis, e farei tudo o que quiserdes, segundo o vosso prazer. - Muito me alegro de assim vos ouvir, disse Monsenhor; mas crede que de outra forma não me escapareis. - Uma coisa vos peço, disse então a moça. Monsenhor, receio muito que a senhora vos tenha ouvido e oiça, e se porventura ela viesse e aqui vos encontrasse, eu seria uma mulher perdida, porque me ela mandaria espancar, senão matar. - Não há-de vir não, disse Monsenhor; dorme a sono solto. - Ah! Monsenhor, tenho tanto medo dela que não me posso fiar. Por isso vos rogo e peço, pela paz de meu coração e para melhor segurança da nossa labuta, que me deixeis ir ver se dorme ou o que faz. - Pela Nossa Senhora, tu não voltarias, disse Monsenhor. - Voltarei sim, disso vos faço juramento, disse ela, voltarei já est'hora. - Assim seja! disse ele, mas vem prestes. - Ora, Monsenhor, se quereis fazer as coisas como convém, disse ela, pegareis nesta peneira e trabalhareis como eu fazia, a fim que, se porventura a senhora estiver acordada, ela me oiça na tarefa em que me ocupo desde a madrugada. - Dá-me cá isso, farei um bom labor, e vê lá se não te demoras. - Não, Monsenhor; mas ponde também esta beatilha na cabeça, disse ela, e passareis por mulher. - Dai cá, disse ele, pardeus, dai cá». Assim enfarpelado com a beatilha, põe-se a peneirar que é maravilha vê-lo, de tão bem que lhe fica. E entretanto a camareira subiu ao quarto e acordou a dama, a quem contou a forma como Monsenhor a havia instado com amores e acometido no momento em que peneirava. «E se vossa mercê quer ver como me consegui escapar e em que ponto ele está, vinde lá abaixo e logo o vereis». Levanta-se logo a senhora, pega no vestido de noite, e em breve se encontrou à porta da saleta onde Monsenhor aplicadamente peneirava. E quando o vê naquele estado, com a estamenha na cabeça, diz-lhe: «Ah! Monsenhor e que é isto? E onde estão as vossas letras, as vossas grandes honras, as vossas ciências e discrições?» E Monsenhor, que se vê bem enganado, respondeu sem mais nem menos: «Na ponta do meu membro, senhora, foi aí que hoje concentrei tudo». Então, grandemente desapontado e pesaroso com a criada desfez-se da peneira e da beatilha e sobe para o quarto. E a senhora, que o segue, recomeça o seu sermão, de que Monsenhor não faz caso algum. Uma vez pronto, mandou preparar a mula, e vai-se ao palácio onde conta a sua aventura a vários gentis-homens que muito gargalharam com isso. E segundo depois me foi dito, apesar da grande ira que o senhor no momento sentiu contra a servente, mais tarde, pela palavra e pelos haveres, a ajudou a encontrar um bom partido.

Tradução de Olinda Kleiman 